\title{
Bifunctional Mesoporous Organosilica Materials and Their Application in Catalysis: Cooperative Effects or Not?
}

\author{
Andreas Kuschel, Malte Drescher, Thomas Kuschel, and Sebastian Polarz* \\ Department of Chemistry, University of Konstanz, 78457 Konstanz, Germany \\ Received August 30, 2009. Revised Manuscript Received January 18, 2010
}

\begin{abstract}
The synthesis and characterization of a new periodically ordered mesoporous organosilica material (PMO) containing aniline as a bridging organic building block is presented. Furthermore, the coordination of the vanadyl cation $[\mathrm{VO}]^{2+}$ to the carboxy function of a second PMO material containing benzoic acid is described. Bifunctional materials containing both mentioned functional groups in different amounts (HOOC- $\left.\mathrm{PhSi}_{2} \mathrm{O}_{3}\right)_{1-x}\left(\mathrm{H}_{2} \mathrm{~N}-\mathrm{PhSi}_{2} \mathrm{O}_{3}\right)_{x}$ have been prepared. The investigation of the dipolar coupling of $[\mathrm{VO}]^{2+}$ coordinated to the benzoic acid groups via EPR spectroscopy has been used to derive a detailed picture about the surface structure of the pores on the molecular scale. The catalytic activity of the bifunctional materials in a two-step chemical transformation is investigated as a possible application. The vanadyl group catalyzes the cleavage of an acetal followed by Knoevenagel condensation catalyzed by aniline. A cooperative effect of the two groups has been observed which is, however, not caused by a special interaction between the groups but is due to pure statistic reasons.
\end{abstract}

\section{Introduction}

Catalysis possesses without any doubt an actual and future paramount importance. The recent progress regarding the synthesis of fine chemicals via molecular, metal containing catalysts in the homogeneous phase is impressive. It is the specific interplay between the metal and the attached ligands which is responsible for the high selectivity and activity in many molecular catalysts. On the other hand, one of the advantages of heterogeneous catalysis is the ease of separation of products and catalyst from each other. Therefore, it is a relevant task to bridge from catalytically active, molecular compounds to heterogeneous catalysis. ${ }^{1}$ Consequently, there has been a tremendous and long lasting effort in the immobilization of molecular catalysts on solid supports. ${ }^{2}$ Silica represents the dominant support material because of the numerous possibilities for shaping and for surface modification. ${ }^{3,4}$ For instance, silica with internal surface area of up to

*Author to whom correspondence should be addressed. E-mail: sebastian.polarz@uni-konstanz.de. Fax: (+49)-7531884406.

(1) Coperet, C.; Chabanas, M.; Saint-Arroman, R. P.; Basset, J. M. Angew. Chem., Int. Ed. 2003, 42, 156. Cole-Hamilton, D. J. Science 2003, 299, 1702. Jas, G.; Kirschning, A. Chem.-Eur. J. 2003, 9, 5708.

(2) Kobayashi, S.; Akiyama, R. Chem. Commun. 2003, 449. Corma, A.; Garcia, H. Adv. Synth. Catal. 2006, 348, 1391. Cozzi, F. Adv. Synth. Catal. 2006, 348, 1367.

(3) Corma, A. Chem. Rev. 1997, 97, 2373. Sutra, P.; Brunel, D. Chem. Commun. 1996, 2485. Johnson, B. F. G.; Raynor, S. A.; Shephard, D. S.; Mashmeyer, T.; Thomas, J. M.; Sankar, G.; Bromley, S.; Oldroyd, R.; Gladden, L.; Mantle, M. D. Chem. Commun. 1999, 1167.

(4) Brunel, D. Microporous Mesoporous Mater. 1999, 27, 329.

(5) Beck, J. S.; Vartuli, J. C.; Roth, W. J.; Leonowicz, M. E.; Kresge, C. T.; Schmitt, K. D.; Chu, C. T.; Olson, D. H.; Sheppard, E. W.; McCullen, S. B.; Higgins, J. B.; Schlenker, J. L. J. Am. Chem. Soc. 1992, 114, 10834.
$1000 \mathrm{~m}^{2} / \mathrm{g}$ came into focus after the preparation of mesoporous materials (meso-SiO 2 ) like MCM-41 or SBA-15 had been established. ${ }^{5-7}$ Several excellent review articles focusing on the application of meso- $\mathrm{SiO}_{2}$ in catalysis have already been published. ${ }^{4,8,9}$

Surface modification of meso- $\mathrm{SiO}_{2}$ with organic groups can be achieved in three different ways. ${ }^{10}$ One method is grafting respectively the covalent anchoring to silanol groups present in mesoporous silica. A nice review addressing postfunctionalized meso- $\mathrm{SiO}_{2}$ and their application in catalysis has been published by Ying et al. ${ }^{9}$ Two sources, one of them organically modified, are used for $\mathrm{SiO}_{x}$-network formation in the co-condensation method. The most severe problem associated with the latter methods is the inevitable dilution of the organosilica matrix with pure silica. The composition of the materials has to be described as $\left(\mathrm{SiO}_{2}\right)_{1-x} \cdot\left(\mathrm{RSiO}_{1.5}\right)_{x}$. $x$ can be as high as $25 \%$, but cases of only $5 \%$ modification have also been reported frequently. ${ }^{5,11}$ It is also very difficult to guarantee for a homogeneous distribution of the organic groups along

(6) Kresge, C. T.; Leonowicz, M.; Roth, W. J.; Vartuli, J. C.; Beck, J. S. Nature 1992, 359, 710. Yang, P. D.; Zhao, D. Y.; Chmelka, B. F.; Stucky, G. D. Chem. Mater. 1998, 10, 2033. Polarz, S.; Smarsly, B. J. Nanosci. Nanotechnol. 2003, $2,581$.

(7) Zhao, D.; Feng, J.; Huo, Q.; Melosh, N.; Fredrickson, G. H.; Chmelka, B. F.: Stucky, G. D. Science 1998, 279, 548.

(8) Taguchi, A.; Schueth, F. Microporous Mesoporous Mater. 2005, 77, 1. Climent, M. J.; Corma, A.; Iborra, S.; Navarro, M. C.; Primo, J. J. Catal. 1996, 161, 783. Moeller, K.; Bein, T. Chem. Mater. 1998, 10, 2950. Ciesla, U.; Schueth, F. Microporous Mesoporous Mater. 1999, 27,131

(9) Ying, J. Y.; Mehnert, C. P.; Wong, M. S. Angew. Chem., Int. Ed. $1999,38,56$.

(10) Hoffmann, F.; Cornelius, M.; Morell, J.; Froeba, M. Angew. Chem., Int. Ed. 2006, 45, 3216.

(11) Sutra, P.; Brunel, D. Chem. Commun. 1996, 2485. 
the pore surface. Nevertheless, there was some impressive progress especially regarding the use of organically modified mesoporous silica materials in catalysis. For direct relevance of the work reported here are papers about materials containing two different functional groups and their use in catalysis. ${ }^{12}$ For instance, Lin et al. have described cooperative effects in different condensation reactions (aldol reaction, Henry reaction, and cyanosilylation) observed for the catalytic activity of meso- $\mathrm{SiO}_{2}$ postmodified by acid and base groups. ${ }^{13}$ Davis et al. have investigated the role of the $\mathrm{p} K_{\mathrm{a}}$ value of the used acid in such reactions in further detail. ${ }^{14}$ One further example is the work of Sanchez et al. who have combined the Knoevenagel condensation with an surface immobilized ruthenium hydrogenation catalyst. ${ }^{15}$

Much higher content of organic modification can be reached when sol-gel precursors with a bridging organic group, $\left(\mathrm{R}^{\prime} \mathrm{O}\right)_{3} \mathrm{Si}-\mathrm{R}-\mathrm{Si}\left(\mathrm{OR}^{\prime}\right)_{3}$, are used for the preparation of the so-called periodically ordered mesoporous organosilica (PMO) materials reported by Ozin et al., Inagaki et al., and Stein et al. independent of one another. ${ }^{16}$ It has to be emphasized that, unlike the co-condensation case, $\left(\mathrm{R}^{\prime} \mathrm{O}\right)_{3} \mathrm{Si}-\mathrm{R}-\mathrm{Si}\left(\mathrm{OR}^{\prime}\right)_{3}$ is used in an undiluted form leading to mesoporous materials with the composition $\mathrm{RSi}_{2} \mathrm{O}_{3}$, thus, with a degree of organic modification of $100 \%$. Consequently, the density of the organic groups is very high. ${ }^{17}$ Until recently, the number of functional groups which have been introduced to the pore walls via the PMO technology was relatively restricted. ${ }^{10} \mathrm{PMO}$ materials with walls containing bridging $-\mathrm{CH}_{2}-$, $-\mathrm{CH}_{2} \mathrm{CH}_{2}-,-\mathrm{CH}=\mathrm{CH}-$, and so forth have been reported among others. By attaching two bridging units at the silicon it could be shown that even higher densities of organic groups are accessible. ${ }^{18}$ Much attention was also given to PMO materials prepared from precursors containing a bridging phenyl ring. ${ }^{19,20}$ Such PMOs are very interesting because the $\pi-\pi$ interaction between the phenyl rings can induce partial crystallization of the pore walls. $^{21}$ A limited number of papers describe PMO materials possessing ligand functionality. ${ }^{22}$ For instance, the derivatization of the phenyl ring in the corresponding

(12) Margelefsky, E. L.; Zeidan, R. K.; Davis, M. E. Chem. Soc. Rev. 2008, 37, 1118.

(13) Huh, S.; Chen, H. T.; Wiench, J. W.; Pruski, M.; Lin, V. S. Y. Angew. Chem., Int. Ed. 2005, 44, 1826.

(14) Zeidan, R. K.; Hwang, S. J.; Davis, M. E. Angew. Chem., Int. Ed. 2006, 45, 6332. Zeidan, R. K.; Davis, M. E. J. Catal. 2007, 247, 379.

(15) Goettmann, F.; Grosso, D.; Mercier, F.; Mathey, F.; Sanchez, C. Chem. Commun. 2004, 1240.

(16) Asefa, T.; MacLachan, M. J.; Coombs, N.; Ozin, G. A. Nature 1999, 402, 867. Inagaki, S.; Guan, S.; Fukushima, Y.; Ohsuna, T.; Terasaki, O. J. Am. Chem. Soc. 1999, 121, 9611. Melde, B. J.; Holland, B. T.; Blanford, C. F.; Stein, A. Chem. Mater. 1999, 11, 3302.

(17) Hatton, B.; Landskron, K.; Whitnall, W.; Perovic, D.; Ozin, G. A. Acc. Chem. Res. 2005, 38, 305.

(18) Landskron, K.; Hatton, B. D.; Perovic, D. D.; Ozin, G. A. Science 2003, 302, 266.

(19) Yoshina-Ishii, C.; Asefa, T.; Coombs, N.; MacLachlan, M. J.; Ozin, G. A. Chem. Commun. 1999, 2539.

(20) Guan, S.; Inagaki, S.; Ohsuna, T.; Terasaki, O. J. Am. Chem. Soc. 2000, 122, 5660. Goto, Y.; Inagaki, S. Chem. Commun. 2002, 2410. Yang, Q. H.; Kapoor, M. P.; Inagaki, S. J. Am. Chem. Soc. 2002, 124, 9694. Kapoor, M. P.; Yang, Q. H.; Inagaki, S. Chem. Mater. 2004, 16, 1209.

(21) Inagaki, S.; Guan, S.; Ohsuna, T.; Terasaki, O. Nature 2002, 416, 304

(22) Fujita, S.; Inagaki, S. Chem. Mater. 2008, 20, 891.
PMOs with amino or sulphonium groups has been reported. $^{23-25}$ The authors have introduced the functional group by postfunctionalization starting from the unmodified phenylene PMO. Consequently, only a fraction of the phenylene groups has been functionalized. Matsuoka et al. have reported a very interesting study about the attachment of an organometallic $\mathrm{Cr}(\mathrm{CO})_{3}$ fragment to the phenyl ring of the PMO. ${ }^{24}$ Our group reported about a system which allows for the transformation of the bridging organic entity into all different sorts of functional groups: PMOs containing a bridging 1,3-bis-siloxy benzene derivative functionalized with additional substituents in the 5-position, the so-called UKON materials. ${ }^{26,27}$

There are only a few papers reporting about PMOs containing two distinct functional groups. ${ }^{23,28}$ Ozin et al. have prepared a mesoporous organosilica material by cocondensation of a PMO precursor with bridging ethylene function and an alkoxysilane modified by a vinyl group ${ }^{23}$ Alcohol groups could be introduced later by the selective hydroboration of the vinyl functionality. Corriu et al. published an interesting approach in 2006. ${ }^{29}$ A PMO precursor containing a bis-sulfide bridge was co-condensed with an alkoxysilane modified by a terminal amine. The cleavage and oxidation of the $\mathrm{S}-\mathrm{S}$ bridge resulted in sulfonic acid groups located in the pore walls and amine groups at the surface of the pores. It should be noted that the authors had to use a 10-fold excess of $\mathrm{Si}(\mathrm{OEt})_{4}$ for the preparation of their materials.

Some papers about catalytic applications of PMOs have also been published. ${ }^{22,30}$ For instance Corma et al. have reported in a nice paper a material containing a chiral, bridging vanadyl salen complex and its application in catalysis. ${ }^{31}$ However, the authors had to dilute their precursors with $\mathrm{Si}(\mathrm{OEt})_{4}$, and therefore the materials might rather be categorized under the co-condensation category rather than PMOs.

We aim at the synthesis of mesoporous organosilica materials related to the PMO type with walls constructed from two different functional building blocks assembled with geometrical precision. First, we describe the formation of surface bound, catalytically active metal complexes with the benzoic acid groups in UKON2a (A). The second functional group is aniline, and the corresponding PMO UKON2d is reported here for the first time (B). Then, the mesoporous materials containing both groups embedded in the pore walls are described (C). Finally, the influence of the presence of the two groups in a two-step catalytic transformation is reported (D).

(23) Asefa, T.; Kruk, M.; MacLachlan, M. J.; Coombs, N.; Grondey, H.; Jaroniec, M.; Ozin, G. A. J. Am. Chem. Soc. 2001, 123, 8520 .

(24) Kamegawa, T.; Sakai, T.; Matsuoka, M.; Anpo, M. J. Am. Chem. Soc. 2005, 127, 16784.

(25) Ohashi, M.; Inagaki, S. Chem. Comm. 2008, 841

(26) Kuschel, A.; Polarz, S. Adv. Funct. Mater. 2008, 18, 1272

(27) Kuschel, A.; Polarz, S. Angew. Chem., Int. Ed. 2008, 49, 9513.

(28) Hunks, W. J.; Ozin, G. A. Adv. Funct. Mater. 2005, 15, 259. Cho, E. B.; Kim, D.; Jaroniec, M. J. Phys. Chem. C 2008, 112, 4897.

(29) Alauzun, J.; Mehdi, A.; Reye, C.; Corriu, R. J. P. J. Am. Chem. Soc. 2006, 128, 8718 .

(30) Yang, Q.; Liu, J.; Zhang, L.; Li, C. J. Mater. Chem. 2009, 19, 1945.

(31) Baleizao, C.; Gigante, B.; Das, D.; Alvaro, M.; Garcia, H.; Corma, A. Chem. Commun. 2003, 1860 


\section{Experimental Section}

All reactions were performed with dried glassware under exclusion of air and moisture if not indicated otherwise. All chemicals were obtained from Aldrich and were dried and purified carefully. 1,3-Bis-tri-iso-propoxysilyl-5-bromobenzene, 3,5-bis-tri-iso-propoxysilylbenzoic acid, and the UKON2a material were prepared via procedures described in literature. ${ }^{26,27}$

Preparation of the Vanadyl-Containing PMO VO@UKON2a. A total of $0.1 \mathrm{~g}$ of UKON2a is dried at $100{ }^{\circ} \mathrm{C}$ under vacuum for $15 \mathrm{~h}$. A solution of $0.5 \mathrm{~g}$ of $\mathrm{VO}(\mathrm{acac})_{2}(1.9 \mathrm{mmol})$ dissolved in $5 \mathrm{~mL}$ of chloroform is added. The mixture is refluxed overnight, and the resulting green/yellow solid is filtered off and is washed several times with $50 \mathrm{~mL}$ of chloroform. To remove the remaining $\mathrm{VO}(\mathrm{acac})_{2}$ from the pores the material is stirred two times in $50 \mathrm{~mL}$ of $\mathrm{CH}_{2} \mathrm{Cl}_{2}$ overnight. Washing is repeated with $20 \mathrm{~mL}$ of $\mathrm{CH}_{2} \mathrm{Cl}_{2} / 1 \mathrm{~mL}$ of pyridine. After filtering and washing with small portions of $\mathrm{CH}_{2} \mathrm{Cl}_{2}$ the material is dried under vacuum. FT-IR (ATR): 1049 ( $\mathrm{Si}-\mathrm{O}$, $\mathrm{Si}-\mathrm{C}), 1445$ ( $\mathrm{COO}^{-}$-symmetric valence vibration), 1523 $\left(\mathrm{COO}^{-}\right.$asymmetric valence vibration), 1583 (aromatic $\mathrm{C}-\mathrm{C}$ ), $1706(\mathrm{C}=\mathrm{O}), 2978(\mathrm{C}-\mathrm{H})$, and $3350(\mathrm{O}-\mathrm{H}) . \mathrm{EDX}: \mathrm{V} / \mathrm{Si} / \mathrm{O} \sim 1 /$ $16 / 40$.

Synthesis of 3,5-Bis-(tri-iso-propoxysilyl)-aniline (2). A total of $0.18 \mathrm{~mL}^{\text {of }}{ }^{\mathrm{t}} \mathrm{Bu}_{3} \mathrm{P}(0.49 \mathrm{M}$ solution in THF $)$ is added to $0.05 \mathrm{~g}$ of $\mathrm{Pd}(\mathrm{dba})_{2}$ in $5 \mathrm{~mL}$ of THF. The mixture is stirred for $30 \mathrm{~min}$, and $0.5 \mathrm{~g}$ of 1,3-bis-tri-iso-propoxysilyl-5-bromobenze (1) (0.88 $\mathrm{mmol}$ ) in $20 \mathrm{~mL}$ of THF is added and then stirred for $30 \mathrm{~min}$. After the addition of $0.05 \mathrm{~g}$ of $\mathrm{LiCl}$ and $0.4 \mathrm{~g}$ of $\left[\left(\mathrm{Me}_{3} \mathrm{Si}\right)_{2} \mathrm{~N}\right]_{2} \mathrm{Zn}$ $(1.06 \mathrm{mmol})$ the mixture is heated to $60{ }^{\circ} \mathrm{C}$ for $72 \mathrm{~h}$, filtered through a short column of silica gel 60 , and washed with $\mathrm{CH}_{2} \mathrm{Cl}_{2}$. An orange gel is obtained after solvent removal. It is dissolved in $20 \mathrm{~mL}$ of ${ }^{\mathrm{i}} \mathrm{PrOH}$, and $0.3 \mathrm{~mL}$ of $\mathrm{Me}_{3} \mathrm{SiCl}$ are added. The mixtured was stirred overnight. The evolving hydrochloric acid was trapped by pyridine. The product was obtained after centrifugation with pentane. Column chromatography (silica gel $60 ; \mathrm{CH}_{2} \mathrm{Cl}_{2} /$ AcOEt $30 / 1 \rightarrow 20 / 1 \rightarrow 10 / 1 \rightarrow 0 / 1$ ) was applied for further purification. Finally $0.35 \mathrm{~g}(80 \% ; 0.70 \mathrm{mmol})$ of a slightly orange solid were obtained. ${ }^{1} \mathrm{H}$ NMR $(400 \mathrm{MHz}$, $\left.\mathrm{CDCl}_{3}\right): \delta /[\mathrm{ppm}]: 1.13\left(\mathrm{~d}, 36 \mathrm{H},{ }^{3} J=6.1 \mathrm{~Hz},{ }^{\mathrm{i}} \mathrm{Pr}-\mathrm{CH}_{3}\right) ; 4.18$ (sept, $6 \mathrm{H},{ }^{3} \mathrm{~J}=6.1 \mathrm{~Hz},{ }^{\mathrm{i}} \operatorname{Pr}-\mathrm{CH}$ ); 7.80 (s, 2H, o-arom. H); 7.94 (s, 1H, p-arom. H); $10.71\left(\mathrm{~s}, 3 \mathrm{H}, \mathrm{NH}_{3}{ }^{+}\right) .{ }^{13} \mathrm{C} \mathrm{NMR}(100.61$ $\mathrm{MHz}_{\mathrm{CDCl}}$ ): $\delta /[\mathrm{ppm}]: 25.5\left({ }^{\mathrm{i}} \mathrm{Pr}-\mathrm{CH}_{3}\right) ; 65.7\left({ }^{\mathrm{i}} \mathrm{Pr}-\mathrm{CH}\right) ; 129.5$ (p-arom. C); 130.8 (Si-arom. C); 135.0 (o-arom. C); 141.7 (arom. $-\mathrm{NH}_{3}{ }^{+}$). FT-IR (ATR): $v /\left[\mathrm{cm}^{-1}\right]$ : $1026(\mathrm{Si}-\mathrm{O}) ; 1116$ (Si-C); 1368-1577 (aliph. + arom. C-C); $1621\left(\mathrm{C}-\mathrm{NH}_{3}{ }^{+}\right)$; 2892-2980 (aliph + arom. C-H); 3375, $3462\left(\mathrm{NH}_{3}{ }^{+}\right)$. EI-MS $(70 \mathrm{eV}): m / z: 537\left(\mathrm{M}^{+}\right)$(very weak), $501(-\mathrm{HCl})$ (main peak); 486 (-Me); 442 (-Oi $\mathrm{Pr})$.

Mesoporous Organosilica Material with $\mathrm{Ph}-\mathrm{NH}_{2}$ as a Bridging Organic Group (UKON2d). A total of $0.5 \mathrm{~g}$ of precursor (2) (0.93 $\mathrm{mmol}$ ) and $0.295 \mathrm{~g}$ of Pluronic P123 are dissolved in $1.6 \mathrm{~g}$ of EtOH. A total of $0.29 \mathrm{~g}$ of $\mathrm{HCl}(1 \mathrm{M})$ is added drop by drop. The sols are aged in an open container for around one week. The resulting monolithic pieces are dried in a vacuum at $100{ }^{\circ} \mathrm{C}$ for $24 \mathrm{~h}$. The template is removed by extraction first in $25 \mathrm{~mL}$ of $\mathrm{H}_{2} \mathrm{O}$ and $25 \mathrm{~mL}$ of $\mathrm{H}_{2} \mathrm{SO}_{4}$ (concd) at $90{ }^{\circ} \mathrm{C}$ and then in $25 \mathrm{~mL}$ EtOH and $25 \mathrm{~mL} \mathrm{HCl}$ (concd) at $60^{\circ} \mathrm{C}$. Complete removal of the Pluronic occurs within 2-4 days. The deprotonation of the Ph$\mathrm{NH}_{3}{ }^{+}$groups was achieved by treatment with triethylamine followed by extensive washing.

Bifunctional PMOs Containing VO@COOPh and $\mathrm{Ph}_{\mathbf{N}} \mathrm{NH}_{2}$. The materials were prepared similar to the method described for the synthesis of UKON2d. However, mixtures containing different ratios of the two sol-gel precursors 3,5-bis-(tri-iso-propoxysilyl)aniline and 3,5-bis-tri-iso-propoxysilylbenzoic acid were used. The composition of the resulting mesoporous organosilica materials can be described as (HOOC-PhSi $\left.{ }_{2} \mathrm{O}_{3}\right)_{1-x}\left(\mathrm{H}_{2} \mathrm{~N}-\mathrm{PhSi}_{2} \mathrm{O}_{3}\right)_{x}$. The treatment with a solution of the vanadyl cation is performed like described for VO@UKON2a.

PMOs Containing VO@COOPh and Ph-Br. The materials were prepared similar to the method described for the synthesis of VO@UKON2a. However, mixtures containing different ratios of the two sol-gel precursors 1,3-bis-(tri-iso-propoxysilyl)-5-bromobenzene (1) and 3,5-bis-tri-iso-propoxysilylbenzoic acid were used. The composition of the resulting, mesoporous organosilica materials can be described as $\left(\mathrm{HOOC}-\mathrm{PhSi}_{2} \mathrm{O}_{3}\right)_{1-x}\left(\mathrm{Br}-\mathrm{PhSi}_{2} \mathrm{O}_{3}\right)_{x}$. The treatment with a solution of the vanadyl cation is performed like described for VO@UKON2a.

Catalytic Investigations Using the Bifunctional PMO Materials. The material $\left([\mathrm{VO}]_{0.5} \mathrm{OOC}-\mathrm{PhSi}_{2} \mathrm{O}_{3}\right)_{0.5}\left(\mathrm{H}_{2} \mathrm{~N}-\mathrm{PhSi}_{2} \mathrm{O}_{3}\right)_{0.5}$ is given as an example. A total of $35 \mathrm{mg}$ of a bifunctional PMO material is dried in vacuum. A mixture of freshly distilled benzyldioxolan $(0.1 \mathrm{~g}, 0.69$ $\mathrm{mmol})$ and $0.75 \mathrm{~g}$ of ethyl cyano-acetate $(0.69 \mathrm{mmol})$ is added. The reaction mixture is heated to $62^{\circ} \mathrm{C}$ for $15 \mathrm{~h}$. The material is filtered off, and the products are analyzed. ${ }^{1} \mathrm{H} \mathrm{NMR}\left(400 \mathrm{MHz} \mathrm{CDCl}_{3}\right) \delta /[\mathrm{ppm}]$ : $1.24\left(\mathrm{t},{ }^{3} \mathrm{~J}=7.2 \mathrm{~Hz}, \mathrm{H}_{3} \mathrm{C}-\mathrm{CH}_{2}-\mathrm{O}-\right.$ ethyl cyano-acetate); $1.32(\mathrm{t}$, ${ }^{3} \mathrm{~J}=7.1 \mathrm{~Hz}, \mathrm{H}_{3} \mathrm{C}-\mathrm{CH}_{2}-\mathrm{O}$-ethyl-2-cyano-3-phenylacrylate); 3.38 (s, bridging- $\mathrm{CH}_{2}$-ethyl cyano-acetate); 3.96 ("m", $\mathrm{O}-\mathrm{CHH}^{\prime}-$ $\mathrm{C} H \mathrm{H}^{\prime}-\mathrm{O}$-benzyldioxolan); 4.05 ("m”, $\mathrm{O}-\mathrm{CH} H^{\prime}-\mathrm{CH} H^{\prime}-\mathrm{O}-$ benzyldioxolan); 4.19 (q, ${ }^{3} \mathrm{~J}=7.2 \mathrm{~Hz}, \mathrm{H}_{3} \mathrm{C}-\mathrm{CH}_{2}-\mathrm{O}-$ ethyl cyanoacetate); 4.31 (q, ${ }^{3} \mathrm{~J}=7.1 \mathrm{~Hz}, \mathrm{H}_{3} \mathrm{C}-\mathrm{CH}_{2}-\mathrm{O}$-ethyl-2-cyano3-phenylacrylate); 5.73 (s, CH-benzyldioxolan); 7.3-8.1 (CH-arom of all products and educts; detailed analysis not possible); 8.18 (s, CH-ethyl-2-cyano-3-phenylacrylate); 9.94 (s, CHO-benzaldehyde). The occurrence of the different reactants and products was monitored by ${ }^{1} \mathrm{H} \mathrm{NMR}$, and the qualitative integration of the characteristic signals allowed the observation of the change in concentration of these species. The total conversion in $[\%]$ is defined as the amount of product III formed in the experiment in relation to the full transformation of the entire amount of reactant I into product III. Although there are only small deviations regarding the specific surface area of the different PMO materials prepared in the current work, possible effects have been considered by dividing the value for the total conversion through the internal surface area obtained from BET evaluation of $\mathrm{N}_{2}$-physisorption data.

EPR Measurements and Analysis. All experiments were performed at room temperature. A Bruker Elexsys E580 X-band spectrometer equipped with a Super High-Q microwave-cavity ER 4122SHQE was used. Performing modulated field sweeps containing 1024 data points (total accumulated sweep time ca. $900 \mathrm{~s}$ ) a modulation frequency of $100 \mathrm{kHz}$ was used. Modulation amplitude of $12.5 \mathrm{G}$ has been chosen such that the signal was not distorted. Spectrometer control and data postprocessing were performed by the Bruker Xepr software. Since the line width of the EPR spectra depends among other factors also on the spin-spin interaction, the spectral second moment was used to quantify this interaction. Therefore, sample $x=0.1$ with a spectrum SM(B) was compared to sample $x=1$ featuring spectrum $\mathrm{SD}(\mathrm{B})$. The difference of spectral second moments $\langle\Delta \mathrm{B} 2\rangle$ was calculated according to the following equation: ${ }^{32}$

$$
\left\langle\Delta \Delta B^{2}\right\rangle=\frac{\int\left(B-B_{\mathrm{FD}}\right)^{2} S_{\mathrm{D}}(B) \mathrm{d} B}{\int S_{\mathrm{D}}(B) \mathrm{d} B}-\frac{\int\left(B-B_{\mathrm{FS}}\right)^{2} S_{\mathrm{M}}(B) \mathrm{d} B}{\int S_{\mathrm{D}}(B) \mathrm{d} B}
$$


Chart 1. Modification of the PMO UKON2a with $[V=O]^{2+}$

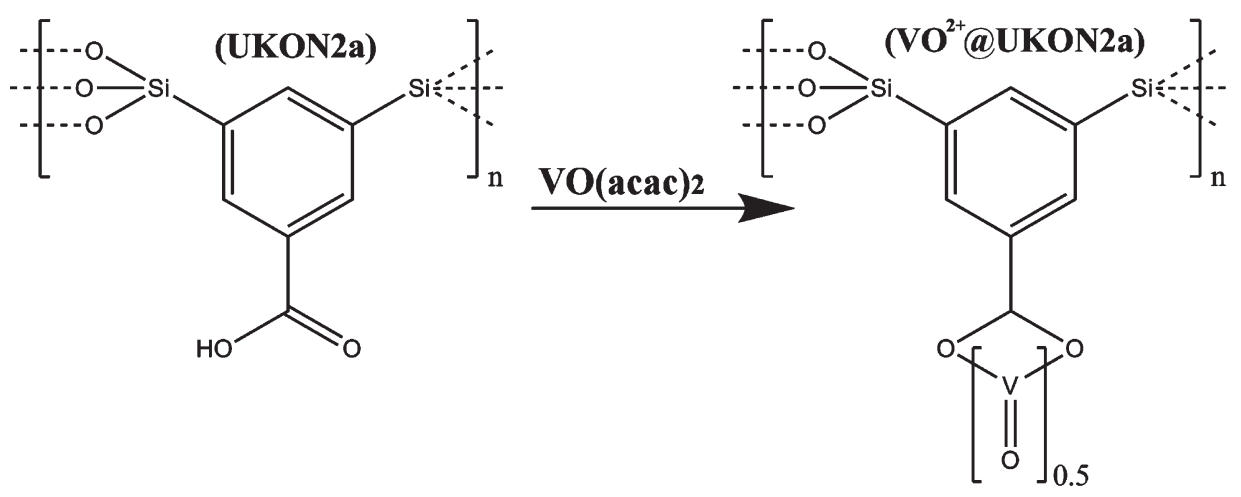

where $S_{\mathrm{D}}(B)$ is the absorption spectrum broadened due to dipolar spin-spin interaction, $S_{\mathrm{M}}(B)$ is the absorption spectrum with negligible spin-spin interaction, and $B_{\mathrm{Fi}}$ and $B$ are the first spectral moments and the magnetic field, respectively. The absorption EPR spectra were baseline corrected using Xepr software (Bruker Biospin, Rheinstetten, Germany), and the first and second moment were calculated numerically using MatLab (MathWorks, MA, U.S.A.). To estimate the average nearest neighbor distance all pair interactions to nearest neighbors have been taken into account

$$
\left\langle\Delta \Delta B^{2}\right\rangle=\sum_{t}\left\langle\Delta \Delta B_{t}{ }^{2}\right\rangle=p \sum_{t} \frac{1}{d_{t}{ }^{6}}
$$

where the second moments of each two-particle interaction are added $^{33}$ and where $d$ is the spin-spin distance and $p=1.56 \times$ $10^{60} \mathrm{~T}^{2} \mathrm{~m}^{-6} \cdot{ }^{32}$

\section{Results and Discussion}

3.1. Modification of UKON2a with a Catalytically Active Metal Center (A). The carboxylic group of UKON2a should be able to coordinate to a range of metal centers. For the current paper it is important that a catalytically active species is used which coordinates exclusively to the $-\mathrm{COOH}$ group. Other and undesirable possibilities are either the amine function in UKON2d later on (see paragraphs 3.2 and 3.3) or surface silanol groups. The vanadyl cation $\left[\mathrm{V}^{\mathrm{IV}} \mathrm{O}\right]^{2+}$ was selected because it can be utilized as a catalyst in various chemical transformations. ${ }^{34}$ The successful binding of $[\mathrm{VO}]^{2+}$ can be achieved if the $\mathrm{p} K_{\mathrm{a}}$ value of the corresponding acid of the ligand attached to $[\mathrm{VO}]^{2+}$ is significantly higher than that of benzoic acid $\left(\mathrm{p} K_{\mathrm{a}}=4.22\right)$. After treatment of UKON2a with an aqueous solution of [VO]SO $\mathrm{V}_{4}\left(\mathrm{p} K_{\mathrm{a}}=\right.$ $-3)$, no uptake of $[\mathrm{VO}]^{2+}$ could be determined. The latter result shows as well that the vanadyl cation exhibits no tendency to bind to $\mathrm{Si}-\mathrm{OH}$ functions located on the surfaces of the pore walls. As opposed to this, the reaction of UKON2a with [VO] $(\mathrm{acac})_{2}\left(\mathrm{p} K_{\mathrm{a}}(\mathrm{acac})=8.99\right)$ leads to

(33) Abragam, A. The Principles of Nuclear Magnetism; Oxford University Press: Oxford, 1961

(34) Vedrine, J. C.; Millet, J. M. M.; Volta, J. C. Catal. Today 1996, 32 , 115. Harvey, J. N.; Diefenbach, M.; Schroder, D.; Schwarz, H. Int. J. Mass Spectrom. 1999, 182, 85. Baran, E. J. J. Inorg. Biochem. 2000, 80,1 .

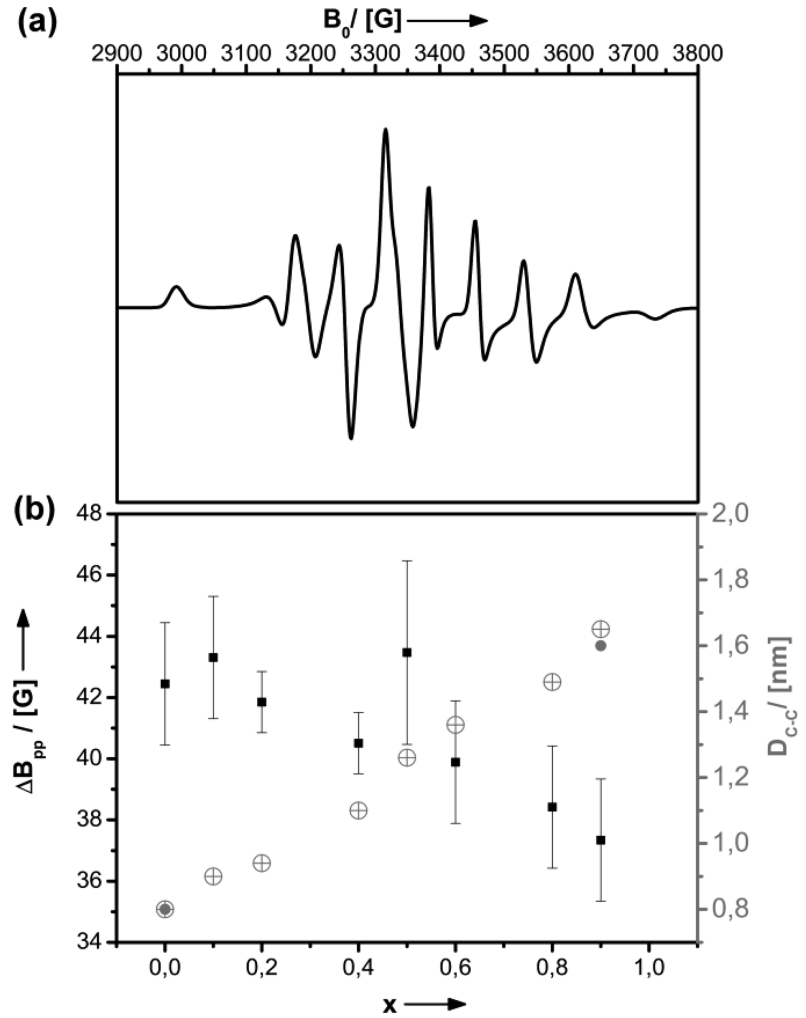

Figure 1. (a) EPR spectrum of $[\mathrm{V}=\mathrm{O}]^{2+} @ \mathrm{UKON} 2 \mathrm{a}$. (b) The EPR line broadening $\Delta B_{\mathrm{pp}}$ (black squares) and the average distance of two carboxylic groups determined experimentally (gray filled circles) and in comparison to the values obtained from the statistical model (gray crossed circles) are shown as a function of the PMO composition (HOOC$\left.\mathrm{PhSi}_{2} \mathrm{O}_{3}\right)_{1-x}\left(\mathrm{H}_{2} \mathrm{~N}-\mathrm{PhSi}_{2} \mathrm{O}_{3}\right)_{x}$.

the formation of the desired material with $[\mathrm{VO}]^{2+}$ attached to the benzoic acid groups (Chart 1).

Even after diligent washing the signals that are typical for the paramagnetic vanadyl cation implying the superposition of hyperfine-structure lines of ${ }^{51} \mathrm{~V}$, corresponding to the perpendicular and parallel directions of the g-tensor, can be seen in the electron paramagnetic resonance (EPR) spectrum (Figure 1a). ${ }^{35}$ Furthermore, in FT-IR spectra two additional bands at $1523 \mathrm{~cm}^{-1}$ and

(35) Gupta, S.; Khanijo, N.; Mansingh, A. J. Non-Cryst. Solids 1995 , 181, 58. Carl, P. J.; Isley, S. L.; Larsen, S. C. J. Phys. Chem. A 2001, 105, 4563. Smith, T. S.; LoBrutto, R.; Pecoraro, V. L. Coord. Chem. Rev. 2002, 228, 1. Zamotrin.Ea; Kulemin, N. P. Izvestiya Vysshikh Uchebnykh Zavedenii Fizika 1969, 143. 

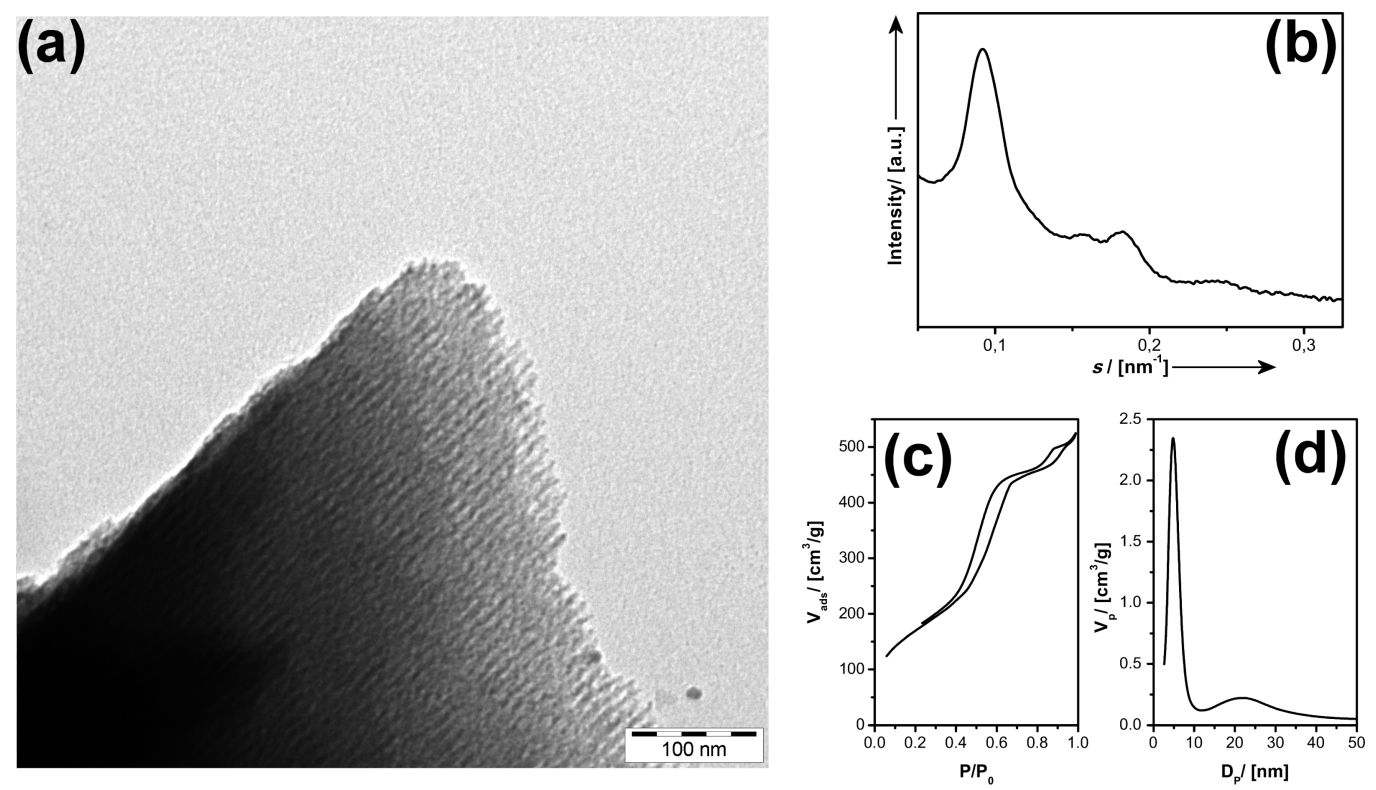

Figure 2. Structural data of UKON2d: TEM migrograph (a), SAXS pattern (b), $\mathrm{N}_{2}$ physisorption isotherm (adsorption and desorption), and BJH poresize distribution function ( $\mathrm{c}$ and $\mathrm{d}$ ).

Chart 2. Preparation of the New PMO Material UKON2d Containing Aniline

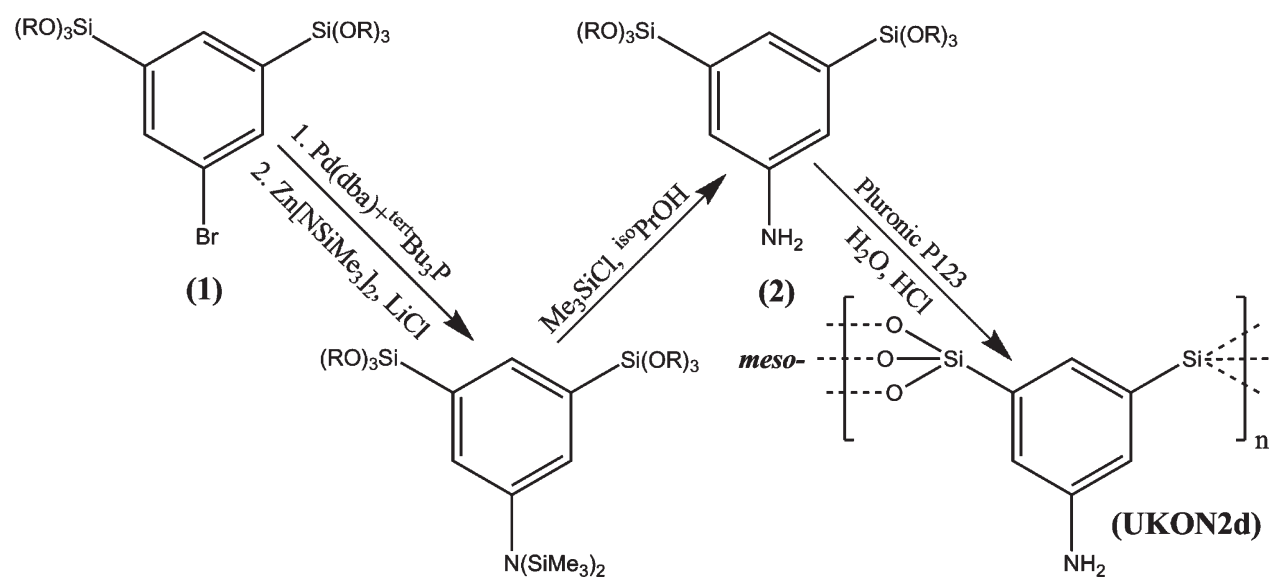

$1445 \mathrm{~cm}^{-1}$ appear which are typical for carboxylate acting as a bidentate ligand (spectra shown in the Supporting Information SI-1). No changes can be observed for the intensity of the band at $3350 \mathrm{~cm}^{-1}$ associated with the $\mathrm{SiOH}$ groups present in the material. It is also important to note that there are no signals present correlating to the acac-ligand which has been cleaved quantitatively. It can be concluded that $[\mathrm{VO}]^{2+}$ coordinates exclusively to the benzoic acid groups in UKON2a. According to a quantitative evaluation of energy dispersive X-ray spectroscopy (EDX) data $25 \%$ of the benzoic groups in UKON2a are involved as ligands whereas two carboxylic groups bind to one vanadyl group (Chart 1). Because we know from previous results that the amount of functional groups which is accessible on the surface of the pore wall of UKON2a is also of the order of $25 \%,{ }^{27}$ the statement that the entire surface is functionalized with $[\mathrm{VO}]^{2+}$ is reasonable.

3.2. New PMO Constructed from Aniline (B). The needed sol-gel precursor, 3,5-bis(tri-iso-propoxysilyl)aniline, can be obtained from the Pd-catalyzed coupling of 3,5-bis(tri-iso-propoxy-siliyl)-bromobenzene with $\mathrm{Zn}$ (hmds) $)_{2}$ (see Chart 2). The resulting PMO was prepared under acidic conditions using the true liquid crystal approach with Pluronic P-123 as a template (Figure 2a). ${ }^{7,36}$

Transmission electron microscopy (TEM) data show a highly ordered material with cylindrical, hexagonally aligned pores (Figure 2a). However, it should be noted that TEM is only a local analytical technique. Therefore, smallangle X-ray scattering (SAXS) was applied as an independent method for the characterization of the structure of UKON2d. Three clear maxima $\left(s_{100}=0.091 \mathrm{~nm}^{-1}, s_{110}=\right.$ $0.157 \mathrm{~nm}^{-1}, s_{200}=0.183 \mathrm{~nm}^{-1}$ ) are present in the SAXS pattern (Figure $2 \mathrm{~b}$ ) indicating a pore to pore distance of $D_{\text {pore-pore }} \approx 10 \mathrm{~nm}$. Even a fourth, weak diffraction maximum can be identified at $s=0.248 \mathrm{~nm}^{-1}$. Such a high number of high order reflections are seen if mesoporous materials possess a well structured pore system. Therefore, the SAXS data confirm the conclusions drawn from TEM

(36) Polarz, S.; Antonietti, M. Chem. Commun. 2002, 2593. Goeltner, C. G.; Antonietti, M. Adv. Mater. 1997, 9, 431. Goeltner, C. G.; Berton, B.; Kraemer, E.; Antonietti, M. Adv. Mater. 1999, 11, 395. 

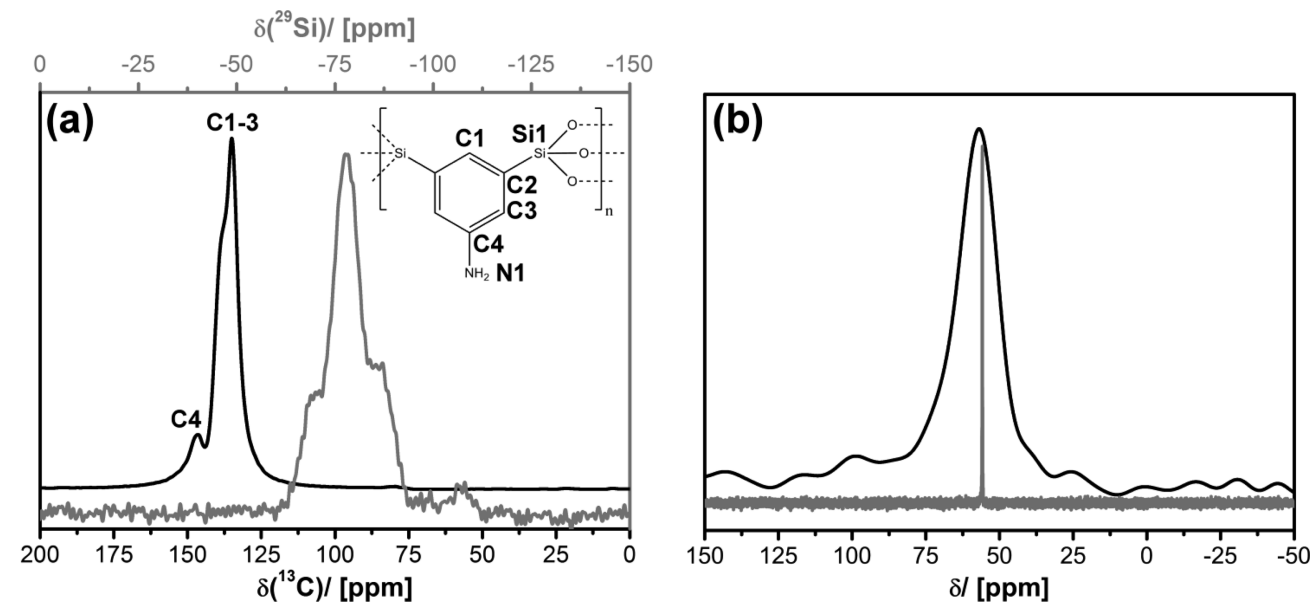

Figure 3. Solid-state NMR data for the new PMO material UKON2d: ${ }^{13} \mathrm{C}$ (a; black graph), ${ }^{29} \mathrm{Si}$ (a; gray graph) and ${ }^{15} \mathrm{~N}$ spectra (b). In (b) a comparison to the spectrum of the precursor 3,5-bis(tri-iso-propoxysilyl) aniline (gray line; measured in $\mathrm{C}_{6} \mathrm{D}_{6}$ ) is shown.

measurements. Next, $\mathrm{N}_{2}$ physisorption data was acquired as shown in Figure 2c. The isotherm of UKON2d possesses a shape which is typical for mesoporous solids with a capillary condensation step at $p / p^{0} \approx 0.57 .^{37}$ The material possesses an internal surface area of $625 \mathrm{~m}^{2} / \mathrm{g}$ determined by the BET method. ${ }^{38}$ The steady increase of adsorbed volume in the pressure range below $p / p^{0}<0.4$ indicates the presence of large micropores $\left(D_{\text {pore }} \approx 2 \mathrm{~nm}\right)$. The pore-size distribution function of UKON2d was determined from the BJH evaluation of the adsorption branch of the isotherm. ${ }^{39}$ A poresize maximum $D_{\mathrm{P}}=4.9 \mathrm{~nm}$ is found (Figure $2 \mathrm{~d}$ ). The pore size determined from $\mathrm{N}_{2}$ physisorption is in good agreement with TEM data. In combination with the SAXS data it can be concluded that pore walls of UKON2d are relatively thick ( $\left.D_{\text {thickness }} \approx D_{\text {pore-pore }}(\mathrm{SAXS})-D_{\text {pore }}\left(\mathrm{N}_{2}\right) \approx 5 \mathrm{~nm}\right)$. The latter finding can also be confirmed by TEM images. It is seen that the pore walls have extensions similar to those of the pores (see Figure 2a).

The chemical nature of UKON2d was investigated via solid-state MAS NMR spectroscopy. The ${ }^{29} \mathrm{Si}$ NMR spectrum of UKON2f (Figure $3 \mathrm{a}$ ) contains the characteristic three signals at $\delta=-70 \mathrm{ppm}$ for $(\mathrm{HO})_{2} \mathrm{R} S i(\mathrm{OSi}) \cong$ $\mathrm{T}^{1},-78 \mathrm{ppm}$ for $(\mathrm{HO}) \mathrm{RSi}(\mathrm{OSi})_{2} \cong \mathrm{T}^{2}$, and $-86 \mathrm{ppm}$ for $\mathrm{RSi}(\mathrm{OSi})_{3} \cong \mathrm{T}^{3}$. ${ }^{19}$ Signals indicating the presence of pure silica $\left(\mathrm{SiO}_{2}\right)$ are not seen demonstrating that the precursor has been used in an undiluted form and that the $\mathrm{Si}-\mathrm{C}$ bonds in UKON2d are stable. In the ${ }^{13} \mathrm{C}$ NMR spectrum only the signals for $\mathrm{C}_{\text {arom }}-\mathrm{NH}_{2}(\delta=147 \mathrm{ppm})$ and the remaining $\mathrm{C}_{\text {arom }}(\delta=135 \mathrm{ppm}, 139 \mathrm{ppm})$ are observed (Figure $3 \mathrm{a}$ ). In addition ${ }^{15} \mathrm{~N}$ NMR data were recorded (Figure $3 \mathrm{~b})$. The chemical shift of the nitrogen atom $(\delta=$ $55.8 \mathrm{ppm}$ ) in the precursor (2) fits very well to the value for pure aniline $(\delta=56.1 \mathrm{ppm})$. Comparison to the solid-

(37) Gregg, S. J.; Sing, K. S. W. Adsorption, Surface Area and Porosity, 4th ed.; Academic Press: New York, 1982; Vol. 2. Rouqerol, J.; Avnir, D.; Fairbridge, C. W.; Everett, D. H.; Haynes, J. H.; Pernicone, N.; Ramsay, J. D.; Sing, K. S. W.; Unger, K. K. Pure Appl. Chem. 1994, 66, 1739.

(38) Brunauer, S.; Emmet, P. H.; Teller, E. J. Am. Chem. Soc. 1938, 60, 309

(39) Barret, E. P.; Joyner, L. G.; Halenda, P. H. J. Am. Chem. Soc. 1951, 73,373 . state NMR spectrum of UKON2d indicates clearly that its composition can be described as $\mathrm{NH}_{2} \mathrm{C}_{6} \mathrm{H}_{3} \mathrm{Si}_{2} \mathrm{O}_{3}$ (see Chart 2).

3.3. PMOs Containing Two Different Functional Groups (C). An even higher level of complexity can be achieved if a PMO material is prepared containing two very different functional groups like in UKON2a and UKON2d organized on the nanoscale. The desired bifunctional PMOs have been synthesized from mixtures of the precursors 3,5-bis(tri-isopropoxysilyl)benzoic acid and 3,5-bis(tri-isopropoxysilyl) aniline in different ratios. Materials with the formal composition of a copolymer (HOOC-PhSi $\left.{ }_{2} \mathrm{O}_{3}\right)_{1-x}\left(\mathrm{H}_{2} \mathrm{~N}-\mathrm{PhSi}_{2} \mathrm{O}_{3}\right)_{x}$ with $(x=0.0,0.1$, ..., 1.0) can be obtained. This can be shown by FT-IR spectroscopy and solid-state NMR spectroscopy. The corresponding data are shown in Figure 4. The main feature in the fingerprint region of the FT-IR spectrum of UKON2a is the band at $1700 \mathrm{~cm}^{-1}$ correlating to the carboxylic group. The characteristic vibrations for the $-\mathrm{NH}_{2}$ function in UKON2d are found at $1623 \mathrm{~cm}^{-1}$ and $1387 \mathrm{~cm}^{-1}$ (see also Supporting Information SI-2). The band at $1700 \mathrm{~cm}^{-1}$ becomes gradually weaker and the bands correlating to aniline stronger with increasing $x$. ${ }^{13}$ C-solid-state NMR spectroscopy was applied as an independent technique to support the conclusions made from FT-IR. Also in ${ }^{13} \mathrm{C}$ NMR it is observed that the signal at $\delta=173 \mathrm{ppm}$ for the carboxy group becomes smaller with increasing $x$.

However, because the FT-IR and solid state NMR methods average over the entire sample there is not yet any information about the distribution of the two different groups on the nanoscale. Four different scenarios are possible which are depicted in Scheme 1. Obviously, the macrophase separation into a physical mixture of two different mesoporous organosilica materials represents an undesired event (see Scheme 1a). It could occur if the two precursors are associated with very different hydrolysis rates or very different solubility. If the latter two properties are only slightly different from each other it could come to microphase separation (Scheme 1b). It can be seen that the majority of the pore surfaces would be 
(a)

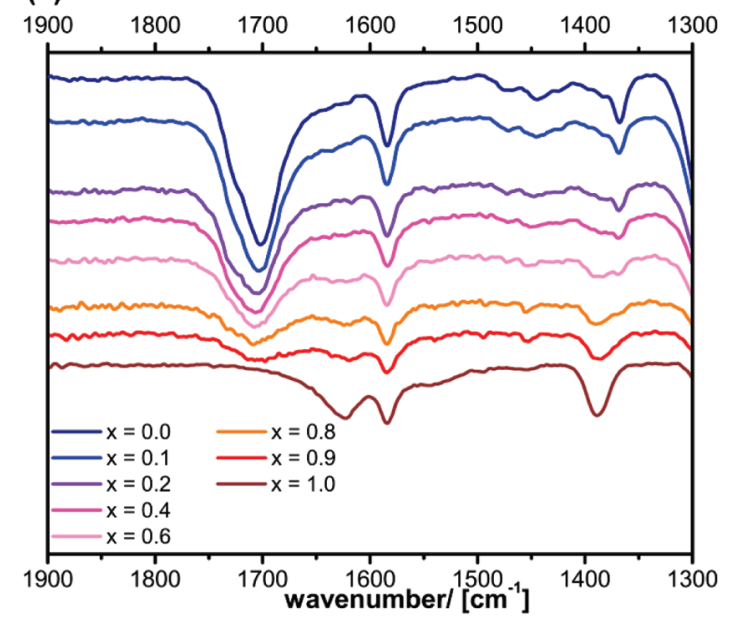

(b)

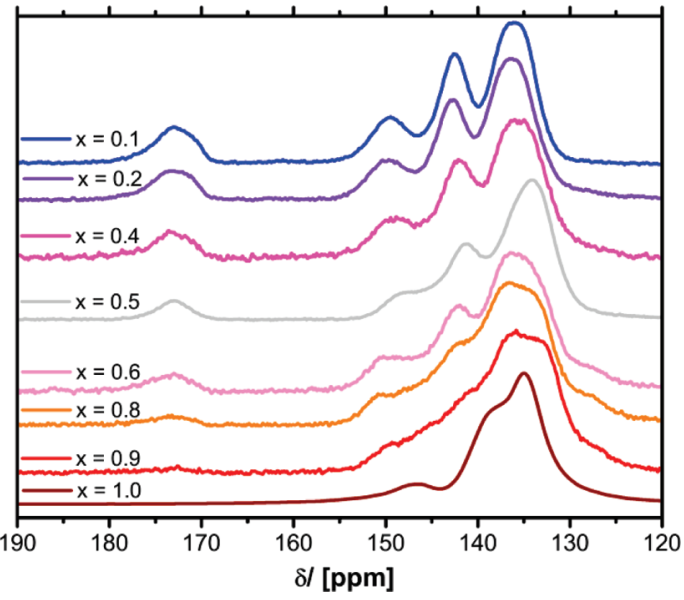

Figure 4. FT-IR spectra (a) and ${ }^{13} \mathrm{C}$-solid state NMR spectra (b) of the bifunctional PMOs (HOOC-PhSi $\left.2_{2} \mathrm{O}_{3}\right)_{1-x}\left(\mathrm{H}_{2} \mathrm{~N}-\mathrm{PhSi}_{2} \mathrm{O}_{3}\right)_{x}$.

Scheme 1. Different Scenarios for the Organization of the Two Functional Groups at the Nanoscale ${ }^{a}$

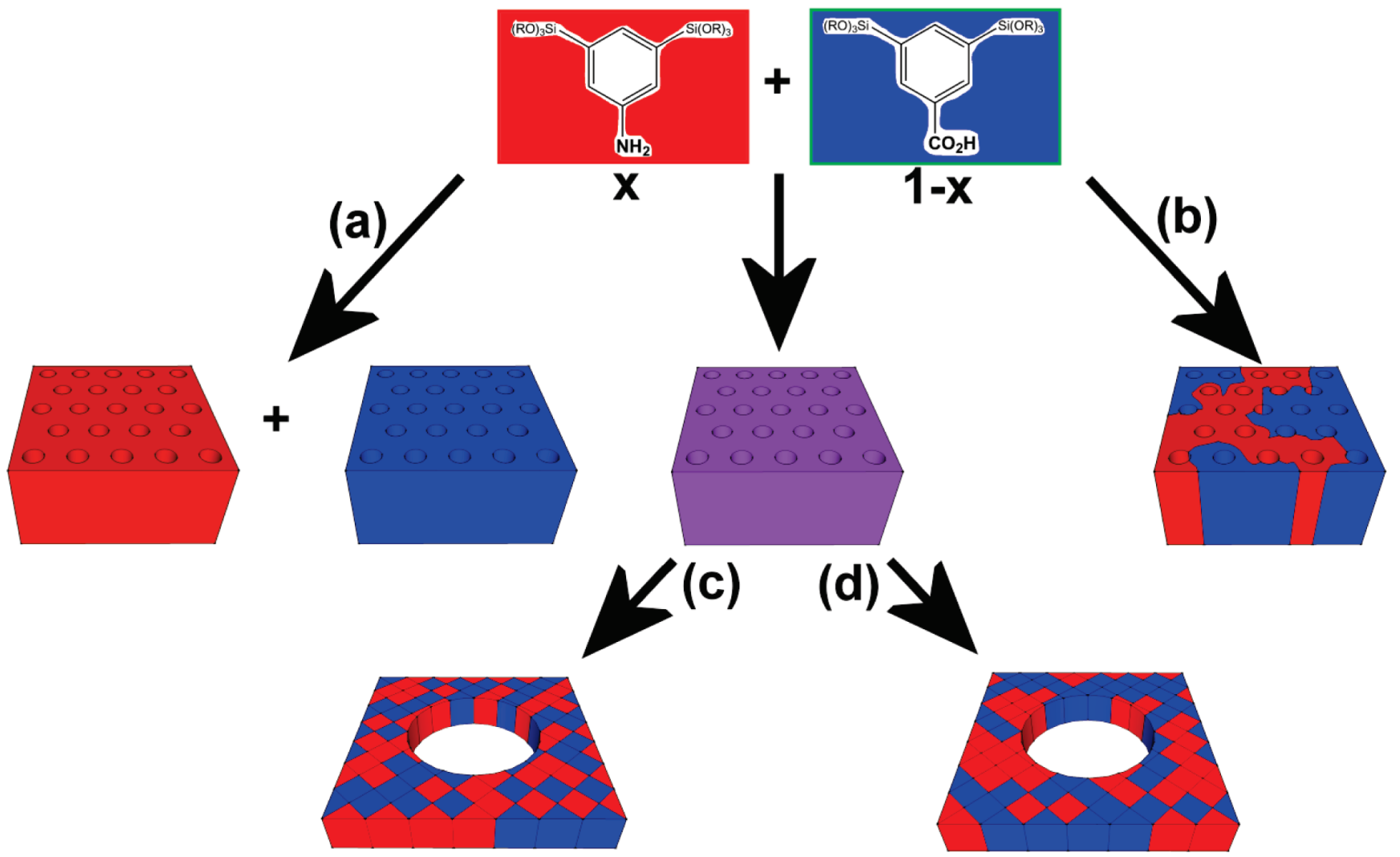

a (a) Macrophase separation, (b) microphase separation, (c) pairing of amine and carboxylic acid, and (d) random mixture.

either covered with carboxylic acid or amine groups. As a result the pore surfaces would not exhibit bifunctional character. Only if phase separation does not occur, one can expect that the surfaces will be characterized by the presence of both functionalities. However, even under these circumstances two further possibilities need to be considered. Either the distribution of the two building blocks is entirely random, or it could be that an attractive interaction between the benzoic acid and aniline building blocks occurs. It should be noted that the event of attraction is less likely because at the $\mathrm{pH}$ used for the preparation of the materials $(\mathrm{pH}=0$; see Experimental Section) benzoic acid and aniline will both be protonated $\left(-\mathrm{COOH}\right.$ and $\left.-\mathrm{NH}_{3}{ }^{+}\right)$. Nevertheless, both possibilities will be discussed (Scheme $1 \mathrm{c}, \mathrm{d}$ ). A cross section of one mesopore and the surrounding pore wall is considered as a model. The pore wall has been divided into equal grids representing the individual building blocks. Then, by using a random generator either an aniline (red) or a benzoic acid (blue) building block is assigned to each grid. The latter method leads to the purely statistical situation, and the result of this scenario is shown in Scheme 1d. 
The following method has been used for the simulation of the interaction between the aniline and the benzoic acid building blocks. In the first step one grid has been assigned randomly. Then, exactly one grid in direct contact to it is set to the second character. The procedure is repeated until all grids are assigned. The result of the latter scenario is shown in Scheme 1c. It is seen that the pores possess bifunctional character for both scenarios but that the distribution of groups in the pore walls is different. The statistic clustering of equal functional groups is much less likely for an interaction between aniline and benzoic acid. It can be concluded that each of the four shown scenarios is connected to a certain composition dependency of the distance distribution functions of the functional groups in the material. Finding the experimental composition dependency of the distance functions should enable us to distinguish between the different scenarios.

Information about the distances between the carboxylate groups as a function of $x$ can be acquired by studying the magnetic interaction of the paramagnetic vanadyl centers via EPR spectroscopy. First, the organosilica material containing only aniline $(x=0$; UKON2d) was treated with a $[\mathrm{VO}](\mathrm{acac})_{2}$ solution. After washing (see Experimental Section) there were no signals found in the EPR spectrum which are characteristic for $[\mathrm{VO}]^{2+}$. It is proven that $[\mathrm{VO}]^{2+}$ does not coordinate to the amine function in UKON2d. Therefore, if the same procedure is applied to the bifunctional materials $\left(\mathrm{HOOC}-\mathrm{PhSi}_{2} \mathrm{O}_{3}\right)_{1-x^{-}}$ $\left(\mathrm{H}_{2} \mathrm{~N}-\mathrm{PhSi}_{2} \mathrm{O}_{3}\right)_{x}$ with $x>0$ one can be sure that $[\mathrm{VO}]^{2+}$ is located exclusively at the benzoic acid entities. The material with $x=0.5$ was investigated as a representative case with scanning electron microscopy (SEM) in backscattering modus (data shown in Supporting Information SI-3). It is seen that the distribution of the elements, in particular the vanadium centers, is absolutely homogeneous. The latter observation rules out the macrophase separation scenario (Scheme 1a). Because the benzoic acid groups become more and more diluted with increasing $x$, the density of $[\mathrm{VO}]^{2+}$ is expected to decrease as well. Interestingly, not only a decrease of the EPR signal intensity is found, but in addition a monotonic dependency of the line-broadening $\Delta B_{\mathrm{pp}}$ of the EPR signals caused by spin-spin coupling as function of $x$ has been observed (dependency shown Figure 1b). The spin-spin coupling is reduced because the distance between the $[\mathrm{VO}]^{2+}$ centers becomes larger. The average distance of $[\mathrm{VO}]^{2+}$ ions present at the pore-surface $D_{\mathrm{C}-\mathrm{C}}$ can be obtained from evaluating the second momentum of the EPR data (see Experimental Section). $D_{\mathrm{C}-\mathrm{C}}(x=0)=$ $0.8 \mathrm{~nm}$ and $D_{\mathrm{C}-\mathrm{C}}(x=0.9)=1.6 \mathrm{~nm}$ have been determined. The experimental value for the distance between two vanadyl groups, respectively, two carboxylate groups in UKON2a $(x=0)$ fits well to the expected value obtained from force-field calculations $D_{\mathrm{C}-\mathrm{C}}($ th. $)=0.8 \mathrm{~nm}$ (see Supporting Information SI-4). Therefore, EPR spectroscopy seems to be a relaible technique for the experimental determination of the required distances. Furthermore, the distinct dependency of $D_{\mathrm{C}-\mathrm{C}}$ on $x$ elimi- nates the possibility of a microphase separation since here the average distance between neighboring carboxylate groups would be more or less independent from composition (see Scheme 1b). Finally, a quantitative correlation between $D_{\mathrm{C}-\mathrm{C}}$ and the composition parameter $x$ has been developed from a statistical evaluation of the grid model mentioned above. An extract of the surface is represented by a $10 \times 10$ grid in which each cell represents one single PMO building block. The carboxy function is randomly assigned to the cells accounting for the predefined composition $x$ as a constraint (see also Supporting Information SI-4), and the distances of the cells containing the $-\mathrm{COOH}$ groups are determined and averaged. The procedure is repeated $10^{5}$ times for each $x$ leading to an averaged value for $D_{\mathrm{C}-\mathrm{C}}$. The resulting dependency of $D_{\mathrm{C}-\mathrm{C}}$ as a function of $x$ is also shown in Figure $1 \mathrm{~b}$. The experimental values for $D_{\mathrm{C}-\mathrm{C}}(x=0)$ and $D_{\mathrm{C}-\mathrm{C}}(x=0.9)$ are reproduced with high precision. Because there is a close agreement between the model and the experimental data, it can be assumed that the building blocks are statistically distributed in the pore walls. The scenario involving the interaction between aniline and benzoic acid building blocks (Scheme 1c) is difficult to exclude for a certainty, but the presented arguments are in favor of the purely statistic assembly (Scheme 1d). In addition, a pair formation of aniline and benzoic acid should be seen as a change in the vibration of the carboxy group in FT-IR spectroscopy. There are no changes of the band at $1700 \mathrm{~cm}^{-1}$ seen for the bifunctional materials in comparison to UKON2a (see Figure 4a).

To the best of our knowledge, this is the first experimentally underpinned picture for the structure of the surfaces of amorphous mesoporous organosilica materials with molecular scale precision. Furthermore, the results suggest that the properties of the surfaces can be tuned by adjusting the composition parameter $x$. One possible application for such materials with adjustable bifunctional surfaces could be in catalysis which is described in the next paragraph.

3.4. Activity in Consecutive Chemical Transformations (D). It is an interesting question if the presence of both different functional groups at the surface of the mesopores might lead to cooperative effects regarding chemical transformations proceeding inside the pore system. Others have also addressed a similar task, however, not with PMO materials. ${ }^{12-15}$ The coordination compounds of $[\mathrm{VO}]^{2+}$ are valuable Lewis acids, and they can, for instance, catalyze the cleavage of an acetal-like benzyldioxolan (see Figure 5; steps I $\rightarrow$ II). ${ }^{40}$ Aniline on the other hand due to its Lewis base characteristics is known to catalyze the Knoevenagel condensation, for instance, of benzaldehyde with cyan-acetic ethyl ester (see Figure 4; steps II $\rightarrow$ III). ${ }^{41}$

(40) Kantam, M. L.; Neeraja, V.; Sreekanth, P. Catal. Commun. 2001, 2, 301

(41) Fiuza, S. M.; VanBesien, E.; Milhazes, N.; Borges, F.; Marques, M. P. M. J. Mol. Struct. 2004, 693, 103. Esteves, M.; Siquet, C.; Gaspar, A.; Rio, V.; Sousa, J. B.; Reis, S.; Marques, M. P. M.; Borges, F. Arch. Pharm. Chem. Life Sci. 2008, 341, 164. Gaspar, A.; Garrido, E. M.; Esteves, M.; Quezada, E.; Milhazes, N.; Garrido, J.; Borges, F. Eur. J. Med. Chem. 2009, 44, 2092. 

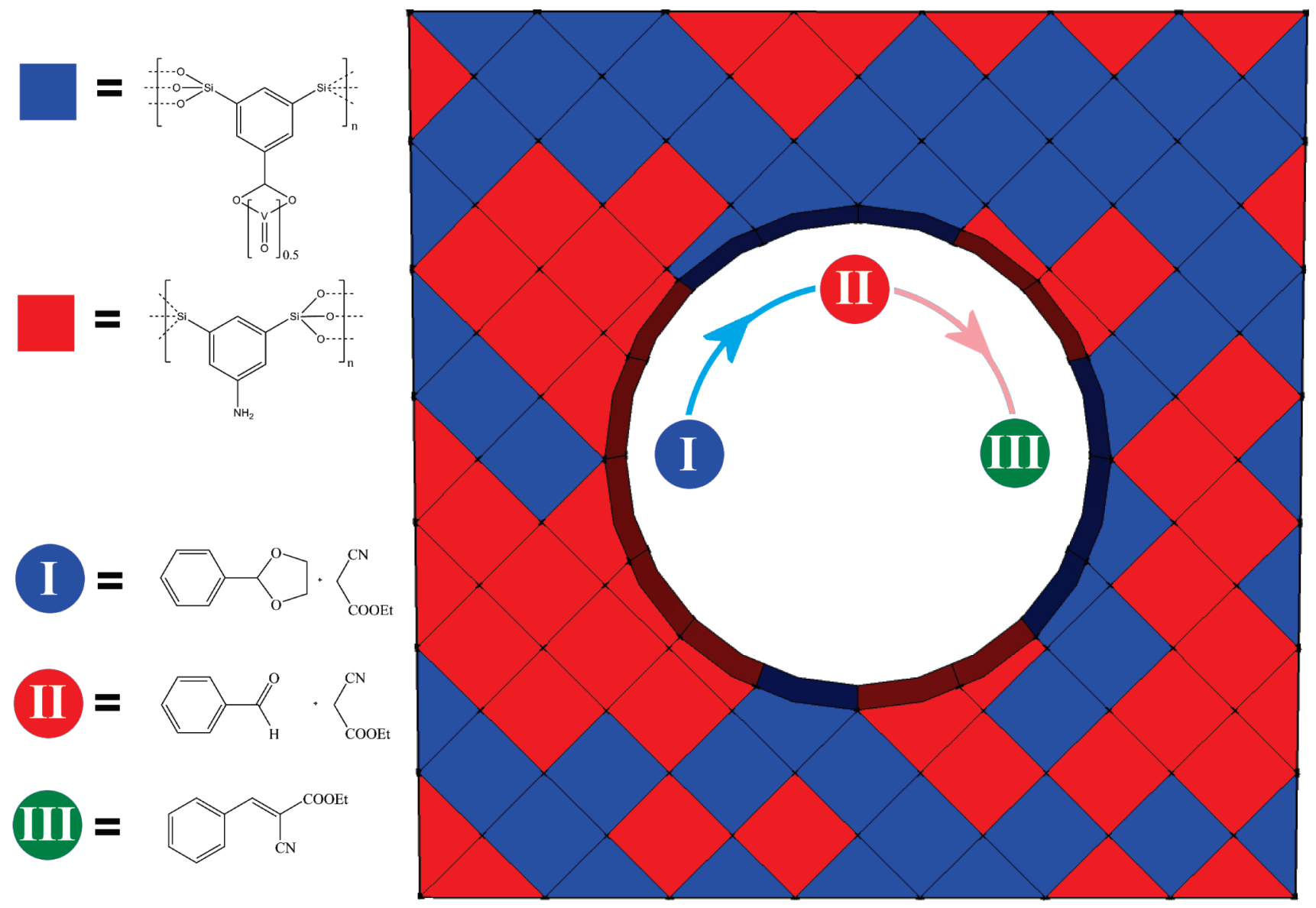

Figure 5. Schematical representation of a two-step chemical transformation (acetal cleavage I $\rightarrow$ II; Knoevenagel condensation II $\rightarrow$ III) performed in the bifunctional PMO. The surfaces of the pores have been systematically varied from aniline rich to aniline poor (and benzoic acid rich) architecture.

The mentioned reactions are also suitable because the individual reaction rate constants are comparable to each other. If the reaction rate constants for one step would be significantly higher, the slower step and the associated catalytic group would dominate the behavior of the entire system.

It is interesting to study the mentioned consecutive reaction sequence I $\rightarrow$ II $\rightarrow$ III in dependence of the architecture of the surfaces containing both groups $\mathrm{VO}^{2+} @ \mathrm{OOCPh}$ and $\mathrm{Ph}-\mathrm{NH}_{2}$. All samples have been treated under identical conditions (reaction temperature, conversion time, etc.). For details see the Experimental Section. It is important to note that despite the fact that there are only small deviations regarding the specific surface area of the different PMO materials prepared in the current work, effects caused by such minor differences have been excluded by dividing the value for the total conversion through the internal surface area obtained from BET evaluation of $\mathrm{N}_{2}$ physisorption data. First, the reference experiments with the monofunctional PMO materials $(x=0 ; x=1)$ have been performed. No noteworthy conversion was observed when the either the pure material UKON2a or pure UKON2d (see Figure 6; $x=1$ ) was used. When VO@UKON2a was present as a catalyst product II could be separated from the reaction mixture in low yield (see Figure $6 ; x=0$ ). A physical mixture (compare to scenario Scheme 1a) of

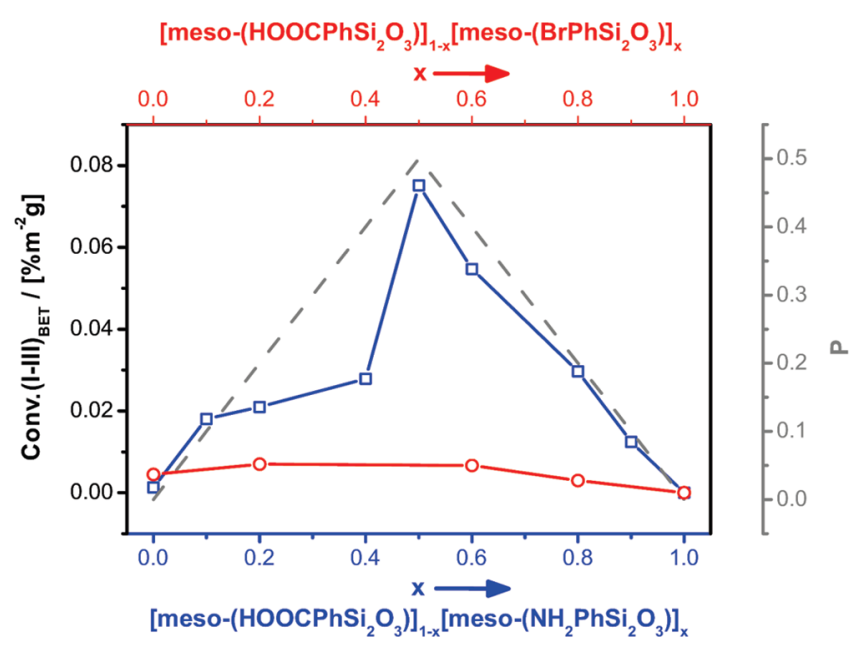

Figure 6. Total conversion normalized against the specific surface area (Conv.(I-III $\left.)_{\mathrm{BET}}\right)$ of the respective materials for the mesoporous organosilicas as a catalyst containing either aniline and the vanadyl cation attached to benzoic acid (blue graph) or the latter and bromobenzene (red graph). The probability $P$ accessing two different functional groups (dashed gray line) as a function of the materials composition $x$ is also shown.

VO@UKON2a and UKON2d was also tested. However, only a vanishing amount of product III has been formed. The latter results demonstrate that the spatial proximity of the two catalytic functions can be a deciding factor. 
Next we wanted to make sure that any observed effects for the bifunctional PMO materials are related to the differing organization of the functional groups on the nanoscale and not any structural differences. Therefore, all materials were characterized by SAXS and $\mathrm{N}_{2}$-physisorption analysis (see Supporting Information SI-3). The main reflection is found at a scattering vector $q \approx 0.70 \mathrm{~nm}^{-1}$ for all samples. Only one reflex can be observed in SAXS which indicates that the mesoporous organosilica materials possess a wormhole pore system. There is a small variation in pore size of $D_{\mathrm{p}}=4.5 \pm 0.3 \mathrm{~nm}$. The resulting differences in internal surface area have been considered by normalizing the total conversion to the specific surface area of the respective material. The results are shown in Figure 5. A maximum in total conversion is seen for a material which is composed of benzoic acid and aniline in equal shares $(x=0.5)$. It is important to note that in principle both steps (I $\rightarrow$ II and II $\rightarrow$ III) can be catalyzed by a Lewis acid, but it is expected that the rate for the Knoevenagel condensation will be relatively small. Therefore, an analogous series of benzoic acid containing materials has been prepared in which aniline is not the second building block but the sol-gel precursor containing a bridging bromo-benzene has been used (see Experimental Section) resulting in materials with the composition (VO@OOC- $\left.\mathrm{PhSi}_{2} \mathrm{O}_{3}\right)_{1-x}\left(\mathrm{Br}^{-} \mathrm{PhSi}_{2} \mathrm{O}_{3}\right)_{x}$. The same catalytic tests were performed. It can be seen that also the mesoporous organosilica materials containing only $\mathrm{VO} @ \mathrm{OOCPh}$ as the catalytically active group lead to a minor conversion I $\rightarrow$ II $\rightarrow$ III, more or less independent of $x$ (Figure 6). Furthermore, it can be deduced from NMR spectroscopy of the reaction mixtures that the conversion $\mathrm{I} \rightarrow \mathrm{II}$ drops almost linear with $x$ (see Supporting Information SI-5). As a result of the same arguments, it can be expected that there would be a monotonic increase of the conversion for step II $\rightarrow$ III with $x$ for materials containing aniline and bromobenzene $\left(\mathrm{Br}-\mathrm{PhSi}_{2} \mathrm{O}_{3}\right)_{1-x}\left(\mathrm{NH}_{2}-\mathrm{PhSi}_{2} \mathrm{O}_{3}\right)_{x}$. Thus, it is obvious that the conversion for the consecutive steps $\mathrm{I} \rightarrow$ II $\rightarrow$ III catalyzed by the bifunctional materials containing benzoic acid and aniline shown in Figure 6 is not a simple superposition of step I $\rightarrow$ II catalyzed by VO@OOCPh and step II $\rightarrow$ III catalyzed by $\mathrm{NH}_{2} \mathrm{Ph}$. The latter findings raise a new question. Is there some special kind of interaction between the two functional groups on the surface of the mesoporous materials, respectively a cooperative effect, or is the variation in diffusion time from the first catalytic center $\left([\mathrm{VO}]^{2+}\right)$ to the second depending on $x$ between them the deciding factor?

Because it could be proven that the distribution of the benzoic acid groups is purely stochastic it can also be concluded that this is true for the aniline building blocks as well. Then, because diffusion through the pore system is a stochastic element the mentioned reaction becomes a Bernoulli experiment reflecting the probability distribution function that a species moving inside the pore system accesses both functional groups. The latter probability distribution function is given by the binomial distribution function

$$
\begin{gathered}
P=\left(\frac{n}{k}\right) p^{k}(1-p)^{n-k} \Longrightarrow P \propto p \equiv f(x) \\
k=1 ; \quad n \gg k
\end{gathered}
$$

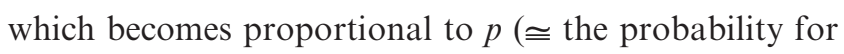
finding a benzoic building block; determined by the composition $x$ ) when $k=1$ meaning that one contact to the aniline building block is sufficient for the conversion (steps $\mathrm{I} \rightarrow \mathrm{II} \rightarrow \mathrm{III}$ ) and $n \gg k$. The probability $P$ as a function of $x$ is also plotted in Figure 6. It possesses a maximum at $x=0.5$. Although the mentioned statistical model is relatively rough it can be seen that it explains the maximum in total yield at $x=0.5$. Furthermore, there is a relatively good qualitative compliance regarding the dependence on $x$ especially for $x>0.5$. It can be concluded that there is no special chemical interaction between aniline and the vanadyl cation. The cooperativity is caused by maximizing the probability of accessing both functional groups during diffusion through the pore system.

\section{Conclusion}

UKON2a is a mesoporous organosilica material constructed from a building block containing a bridging benzoic acid group. ${ }^{26,27}$ The coordination of the vandyl cation $[\mathrm{VO}]^{2+}$ to the carboxylic groups in UKON2a is presented.

A new PMO material constructed from aniline has been reported (UKON2d). It was prepared from a sol-gel precursor containing a bridging aniline unit. The resulting material possessed a well structured pore system of cylindrical channels aligned in a hexagonal packing. Because aniline is one of the most important entities known in organic chemistry we believe that UKON2d could be a bifurcation point for more advanced materials in the future.

Next, bifunctional materials containing both building blocks (aniline and benzoic acid) have been prepared. It could be shown that the distribution of the two groups in the pore walls and on the surfaces is purely statistic. We obtained a refined picture of the molecular structure of the surfaces of such mesoporous organosilica materials. The results indicate that one can achieve a fine-tuning of the chemical character of the pore surfaces by adjusting the composition of the precursor mixture used for the preparation of the materials.

One possible application of such bifunctional mesoporous organosilica materials was probed. The cooperativity of the two groups regarding a two-step chemical process was tested. It could be shown that a maximum in activity measured as yield per time was realized for a material composed of $50 \%$ benzoic acid groups and $50 \%$ aniline groups. However, the observed effects were not caused by any special interaction between the two functional groups. The results could be explained very well by a simple statistical model which considers the probability 
for accessing both functional groups during the course of diffusion through the pore system.

Acknowledgment. We thank the Zukunftskolleg University of Konstanz and the Deutsche Forschungs-gemeinschaft (SP 780/6-1, DR743/2-1) for funding. We thank M. Spitzbarth and $\mathrm{K}$. Guth for the EPR measurements.
Supporting Information Available: SI-1, Additional analytical data for $[\mathrm{VO}]^{2+} @$ UKON2a. SI-2, Additional analytical data for UKON2d. SI-3, Additional analytical data for bifunctional PMO materials. SI-4, Statistical evaluation of the bifunctional materials. SI-5, Investigation of steps I $\rightarrow$ III catalyzed by (VO@OOC- $\left.\mathrm{PhSi}_{2} \mathrm{O}_{3}\right)_{1-x}\left(\mathrm{Br}_{-} \mathrm{PhSi}_{2} \mathrm{O}_{3}\right)_{x}(\mathrm{PDF})$. This material is available free of charge via the Internet at http://pubs.acs.org. 